\title{
South American Perspectives on Sexual Harassment: The Standpoint in Argentina, Brazil, and Chile
}

\author{
Rebecca S. Merkin \\ Baruch College - CUNY, New York, N.Y.
}

\begin{abstract}
This study analyzed questionnaire data about sexual harassment and sexual aggression from 8198 employees in Argentina, Brazil, and Chile. Responses were analyzed using MANOVA, a multivariate analysis of variance. The results of testing differences between the effects of sexual harassment and sexual aggression on job satisfaction consequences were analyzed with a focus on South American perspectives, some of which are different from previous findings in U.S. studies. While previous U.S. studies show sexual harassment causes decreased job satisfaction, the findings of this study revealed that South American employees who were sexually harassed did not show significant decreases in job satisfaction. However, when the same populations were targets of the more serious offense of sexual aggression, they did report significant decreases in job satisfaction. Given the contrast between these results and the results of previous U.S. studies in the literature, these findings indicate that this perspective on sexual harassment differs between cultures. Differences in cultural values were analyzed using G. Hofstede's (2001) cultural dimensions. Further research with regard to the managerial nature of these perceptual differences is indicated.
\end{abstract}

\section{Introduction}

Sexual harassment - the making of unwanted and offensive sexual advances or sexually offensive remarks - is a growing problem in the workplace. Therefore, researchers have shown a great deal of interest in studying sexual harassment of workers (Cortina \& Wasti, 2005; Cortina, Swan, Fitzgerald, \& Waldo, 1998; Dansky \& Kilpatrick, 1997; Gutek, 1985; Huerta, Cortina, Pang, Torges, \& Magley, 2006).

This is due in part to the massive number of negative managerial outcomes found to result from sexual harassment. For example, findings show that workplace sexual harassment is responsible for psychological conditions such as stress, depression, and anxiety that result in declines in organizational performance and productivity (Adams, 1988; Baba, Jamal, \& Tourigny, 1998; Williams, Giuffre, \& Dellinger, 1999). Studies also show that employees' well-being is diminished when they are working in an organizational context perceived as hostile toward women, even in the absence of personally hostile experiences (Miner-Rubino \& Cortina, 2004). Other researchers have found that sexual harassment leads to increases in absenteeism (e.g., Baba, et al., 1998; Hanisch \& Hulin, 1990) and turnover (e.g., Bergman, Langhout, Palmieri, Cortina, \& Fitzgerald, 2002; O'Connell \& Korabik, 2000) and negatively affects affective commitment, job involvement, organizational commitment (Baba et al., 1998; Quick, Murphy, \& Hurrell, 1992; Shupe, Cortina, Ramos, Fitzgerald, \& Salisbury, 2002; Shaffer, Joplin, Bell, Lau, \& Oguz, 2000) and job dissatisfaction (Bond, Punnett, Pyle, Cazeca, \& Cooperman, 2004; Fitzgerald, Drasgow, \& Magley, 1999; Glomb, Munson, Hulin, Bergman, \& Drasgow 1999; Morrow, 
McElroy, \& Phillips, 1994; Munson, Hulin, \& Drasgow, 2000; Gruber, 1992; Gutek \& Koss, 1993; Quick, et al., 1992).

With the above findings in mind, one might logically assume that similar consequences of sexual harassment in the workplace are likely to apply across cultures. Thus, if sexual harassment in the U.S. leads to job dissatisfaction, and if, as Gruber (2003) proposes, perceptions and experiences of sexual harassment are universal, then, the same relationship is likely to exist in other countries such as Argentina, Brazil, and Chile.

Some researchers actually do consider the negative consequences of sexual harassment to extend beyond individual nations to include cross-cultural workgroups and whole multicultural organizations (Barak, 1997; DeSouza \& Solberg, 2003; Sigal \& Jacobsen, 1999; Timmerman \& Bajema, 1999). Moreover, incidences of sexual harassment have steadily climbed throughout the global marketplace, partly due to different cultural values and perceptions (DeSouza \& Hutz, 1996; DeSouza, Pryor, \& Hutz, 1998; Pryor, Desouza, Fitness, Hutz, Kumpf, Lubbert, Pesonen \& Wang, 1997; Sigal, Gibbs, Goodrich, Rashid, Anjum, Hsu, Perrino, Boratav, Carson, Baarsen, van der Pligt, \& Pan, 2005).

Furthermore, some researchers point out that various behaviors considered normal and acceptable in South America would be considered sexually offensive in other countries such as the US (DeSouza \& Hutz, 1996; Shupe et al., 2002). Since sexual harassment incidences in Argentina, Brazil, and Chile are, for the most part, a previously unexplored population, the purpose of this study is to test whether South American perceptions of sexual harassment are similar or different than previously reported U.S. perceptions (e.g., Rospenda, Richman, Ehmke, \& Zlatoper, 2005; Shupe et al., 2002).

\section{Testing the Impact of Sexual Harassment on Job Satisfaction}

Studies of antecedents to sexual harassment in the U.S. show that women experience and perceive more sexual harassment than men (e.g., Gruber \& Bjorn, 1982; West, 1982). In contrast to U.S. findings, tests carried out in Argentina, Brazil, and Chile countries chosen by the International Labour Organization (ILO) as having cities that would provide large numbers of workers for sampling - show that there are no sex differences in whether sexual harassment is perceived (Merkin, In Press) and there is no significant job turnover in response to being sexually harassed (Merkin, 2007). These past studies seem to indicate that sexual harassment is perceived differently in South America and the US. Unfortunately, the number of cross-cultural studies on sexual harassment is fairly limited (Matsui, Kakuyama, Onglatco, \& Ogutu, 1995). Calls have been made for studies on sexual harassment to be culturally rooted (Cortina \& Wasti, 2005; DeSouza, Solberg, \& Elder, 2007; Luthar \& Luthar, 2002). Thus, further testing appears to be warranted with other outcomes to understand South American perceptions better.

\section{Cross-Cultural Perspectives on Sexual Harassment}

Although studies have been undertaken on the perceptions of sexual harassment in the European Union (Elman, 1996; Zippel, 2004), Narodowski (1999) and Stoga (2002) 
advocate the importance of conducting research particularly in South America. South America has experienced growing economic, financial, political, and social unrest following its transition from military rule to democracy (Stoga, 2002; Smith \& Korzeniewicz, 1997; Stark, 2001). These political and subsequent financial changes have also changed the role of women in the South American workplace in that they have become more independent and assertive (Diekman, Eagly, Mlandinic, \& Ferreira, 2005).

Hence, it is important to come to an updated description of workplace sexual harassment reported in South America, to identify managerial issues relating to how employees are being affected by this human resources concern (Cortina, Fitzgerald, \& Drasgow, 2002). Friedrich, Mesquita, and Hatum (2006) point out that the nuances of South American cultures can be over generalized by value-belief theories such as Hofstede's (2001), which identify values and beliefs held by members of cultures and link them to actions and behavior. On the other hand, in the context of reactions to sexual harassment, since our sample employees all perceived they were sexually harassed, this was requiring further fine-graining and contextualization. Thus, this study investigates perceptions of sexual harassment following Luthar and Luthar's (2002) call to study cultural difference in sexual harassment by means of G. Hofstede's (2001) four cultural dimensions.

Hofstede's (2001) four cultural dimensions include (a) individualism-collectivism (IC), (b) power distance (PD) (c) masculinity-femininity (MF) and (d) uncertainty avoidance (UA). They will be used as the framework to analyze South American data on sexual harassment further. Hofstede (2001) explained that individualistic cultures stress individual goals, whereas collectivistic cultures stress group goals. PD is "the extent to which the less powerful members of organizations within a country expect and accept that power is distributed unequally" (p. 98). Hofstede found PD and IC to be positively correlated. The masculinity-femininity (MF) continuum refers to the extent to which a society stresses achievement or nurturance. Hofstede (2001) described cultural masculinity on a continuum ranging from masculine competitiveness to feminine leveling behaviors in the workplace.

According to Hofstede, dimensions consist of points along a continuum with two poles upon which cultures fall. Thus, Hofstede (2001) states that, "masculinity stands for a society in which social gender roles are clearly distinct: Men are supposed to be assertive, tough, and focused on material success; women are supposed to be more modest, tender, and concerned with the quality of life. Femininity stands for a society in which social gender roles overlap in that both men and women are supposed to be modest, tender, and concerned with the quality of life" (p. 297). UA refers to the extent to which people are made nervous by situations they consider to be unstructured, unclear, or unpredictable, and the extent to which they try to avoid such situations by adopting strict codes of behavior and beliefs in absolute truths (Stohl, 1993).

The US, the venue of most sexual harassment studies, is individualistic, weak in PD and UA, and masculine. Based on Hofstede's mean score designations, Argentina, 
Brazil, and Chile are all collective, strong in PD and high in UA - so they have a lot in common culturally. The only point of divergence is that Argentineans are more culturally masculine, unlike Brazilians and Chileans who are culturally feminine (Hofstede, 2001). Given the similar cultural dimensions of the three South American cultures tested (that they are collective, strong in PD, high in UA), it is logical to explore their cultural characteristics with regard to their perspectives on sexual harassment.

\section{Collectivism and Sexual Harassment}

Cultural members develop their identity in light of sexual characteristics and acquire related interpersonal roles and rules of interaction. As Freidrich et al., (2006) explain, there are cultural differences between Argentineans, Brazilians, and Chileans. On the one hand, Brazilians are more egalitarian and informal than Argentineans, and Chileans. On the other hand, Brazilians need more privacy than Argentineans and Chileans. In terms of perceiving sexual harassment, violations of privacy, expectancy violations of how egalitarian one is, and violations of formalities can all lead to an awareness of discomfort.

Once this discomfort is perceived, members of collective cultures tend to favor their in-groups (Triandis, 1988). Thus, collective responses to a peer's sexual-harassment experience tend to provide their peer targets with support from coworkers (Shupe et al., 2002). On the other hand, collective support may act to soften the blow of sexual harassment to the point of explaining it away or minimizing the situation through reframing the events that occurred. This might happen because in collectivistic cultures, the overriding value of harmony causes individuals to avoid conflict such as sexual harassment generally (Chan, Tang, \& Chan, 1999).

This harmony also explains the stronger proclivity for organizational loyalty found in collective cultures (Kim, Triandis, Kagitcibasi, Choi, \& Yoon, 1994). In fact, a number of researchers have suggested that both internal reporting and whistle-blowing directly violates the obligations of loyalty to individuals, ingroups, and organizations (Duska, 1997; MacNab, Brislin, Aguilera, \& Worthley, 2007). Furthermore, researchers assert that because collective societies are organized by tight social frameworks, those in collective cultures have lower propensities for a whistle-blowing type of reporting (Patel, 2003; Sims and Keenan, 1999). Thus, people from collectivistic cultures tend to cover up the flaws of others, look out for their in-group interests, and consequently, generally do not like to make a big issue out of a nebulous possibly sexually harassing experience. It is possible that this propensity to smooth over issues to avoid being conspicuous relates to dissatisfaction reactions to being sexually harassed in that the preferred reaction would be to dismiss the incident.

\section{Power Distance and Sexual Harassment}

The above notion was corroborated by Tavakoli, Keenan, and Crnjak-Karanovic (2003) who found that cultures strong in PD and collectivism were less likely to whistle blow generally. South American cultures that are relatively strong in PD tend to be more accepting of those in authority. Hofstede (1997) points out that those with a strong PD tend to accept the authority of their boss, leading them to be less likely to disrupt the organizational order by reporting sexual harassment. In both collective and strong-PD 
cultures people prefer using indirect communication as opposed to direct communication to handle face-threatening situations like sexual harassment in the workplace (Cocroft \& Ting Toomey, 1994; Merkin, 2006).

Thus, the cultural implications of a strong PD indicate a likelihood not to inform on a perpetrator of sexually harassment. This cultural priority to put stressful situations aside in favor of the authorities could indicate employee acceptance that the world is unfair and thus the employee would not feel a decrease in job satisfaction. In fact, members of strong PD cultures are known not to be troubled by unjust terms (Kublin, 1987). On the other hand, anger as a reaction to inequality and injustice is more likely to be expressed by members of weak PD cultures like the US (Gilson, Fedor, \& Roth, 2005). This is because inequality and injustice are not expected or seen as acceptable in weak power distance cultures (Gudykunst \& Ting-Toomey, 1988; Matsumoto, 1988). The strong-PD society's acceptance of inequality and injustice are highlighted by the fact that PD is significantly and positively correlated with beliefs that the world is unjust (Furnham, 1993). Thus, the strong PD present in Argentina, Brazil, and Chile could predispose their attitudes to express little job dissatisfaction in response to experiencing sexual harassment in the workplace.

\section{Masculinity/Femininity and Sexual Harassment}

In masculine cultures such as the US and Argentina, there are larger differences in values between the sexes (Hofstede, 2001); while feminine cultures, such as Brazil and Chile, emphasize relationships and the preservation of human dignity. There are also fewer sex differences in values, so that both men and women are not bothered by the inequality that underlies some of the mores of their culture. Similarly, while U.S. studies show differences in fairness ratings of respondents (Gilson, et al., 2005); South American studies show no such sex differences in sexual harassment outcomes such as absenteeism on the part of sexual harassment targets (Merkin, In press) or generally (Fiedler \& Blanco, 2006).

Findings show that even with the internal changes that have taken place in South America, particularly in Chile (Moffett, 2006), South American men are viewed as more masculine by South Americans than U.S. men are by U.S. populations. This can be explained by cultural femininity in which both men and women share the same values. Thus, South American values of machismo that emphasize male power over women, masculine sexuality, and aggression (Felix-Ortiz, Abreu, Briano, \& Bowen, 2001) are shared by both men and women alike. Despite the presence of machismo values in Brazil and Chile, with the modernization that is taking place from globalization forces (Leung, Bhagat, Buchan, Erez, \& Gibson, 2005), machismo is becoming less severe.

In addition, there are more emic perspectives which present machismo as more in line with the concept of chivalry, physical strength, attractiveness, and virtue generally (e.g., Valdes, Baron, \& Ponce, 1987). Although Americans tend to stereotype Latin masculinity as lauding aggressive, promiscuous, and dominant communication, others point out that South Americans see the machismo persona to be reflecting dignity, respect, and family values (Good \& Sherrod, 2001). A companion South American 
conception, that of marianismo, indicates that women are long suffering and never complaining because they are morally superior to men (Stevens, 1973), whose infidelity and sexual oppression are accepted (Safa, 1976). Given the machismo and marianismo assumptions in South America, it is more likely that they condone widespread episodes of overtly sexualized communication in the South American workplace as well.

In fact, South American acceptance of differences in the power structures between men and women in the work place explain why employees who are exposed to sexual harassment accept it as natural (Fiedler \& Blanco, 2006). This partly explains why behaviors considered sexually offensive in countries such as the US are considered normal and acceptable in South America (DeSouza \& Hutz, 1996; Shupe et al., 2002). Given the contrast between U.S. and South American findings, a test to see whether differences in perceptions - namely that South American employees experiencing sexual harassment in South America will or will not perceive sexual harassment as a significant offense - the following research question is posed:

\section{Research Question 1: Do South American employees experiencing sexual harassment in South America perceive more job dissatisfaction than employees not experiencing sexual harassment?}

\section{$\underline{\text { UA and Sexual Harassment }}$}

Argentina, Brazil, and Chile are all cultures sharing the values of strong UA (Hofstede, 2001), which refers to the extent to which people are made nervous by situations they consider to be unclear, and the extent to which they try to avoid such situations by adopting strict codes of behavior (Stohl, 1993). One way people in strong UA cultures reduce uncertainty is to look for a structure in their organizations which makes events clearly interpretable and predictable (Hofstede, 1997). Thus, organizations within strong UA cultures are more likely to have rules and procedures to govern the work environment.

Interestingly, Hofstede points out that in strong UA cultures, organizational rules may or may not be followed, nor do they have to be logical or consistent. As long as a rule exists, the members of a culture with a strong UA are more comfortable as "even ineffective rules satisfy people's emotional need for formal structure" Hofstede (1997, p. 121). Thus, while strong-UA Brazil has sexual-harassment laws whose infringement hold fairly heavy fines, most people do not take the law seriously, and it is rarely enforced (Fiedler \& Blanco, 2006).

Furthermore, while anti-sexual-harassment rules may be in place in the workplace, Vitell, Nwachukwu and Barnes (1993, p. 757) point out that "[b]usiness practitioners in countries that are high in uncertainty avoidance ... will be less likely to perceive ethical problems than business practitioners in countries that are low in uncertainty avoidance." Hofstede (1997) observes that it is common for people in strong UA countries to engage in risky behavior, like speeding, if the behavior reduces their feelings of nervousness. Similarly, findings show that people in strong UA countries will also be more likely to use risky aggressive communication as opposed to safe harmonious communication when 
perceiving a situation to be face-threatening (Merkin, 2006), which sexual harassment could arguably be for both the perpetrator and the target. Hofstede (2001) pointed out that uncertainty is to risk as anxiety is to fear. Hence, UA is a gnawing feeling that sometimes leads people to prefer risky communication such as sexual aggression, over harmonious communication which is often safer in terms of the resulting interpersonal ramifications.

Sexual aggression is a more extreme form of abuse than sexual harassment and is comprised of forced sexual activity such as sexual violence in the vein of rape (Krahe, 2001). Husted (1999) reported that countries high in UA are generally more tolerant of corrupt practices, despite their risky and illegal nature.

Conversely, Tavakoli et al. (2003) argue that people in strong UA cultures strive to maintain established reporting structures because not adhering to organizational policy and failing to report rule-breaking activity in a high-UA context could cause stress. In fact, MacNab et al., (2006) found a positive relationship between UA and both internal reporting and whistle-blowing. While sexual harassment may not be perceived as such, the more serious sexual aggression may be more likely to impact employee job satisfaction. However, because of the contrasting views on the impact of UA on reporting serious activities such as sexual aggression, the following research question is posed:

Research Question 2: Will South American employees experiencing sexual aggression in South America have lower job satisfaction than employees not experiencing sexual aggression?

\section{Method}

\section{$\underline{\text { Participants }}$}

This study conducted a secondary analysis on a sample data set from a larger collection conducted by the InFocus Programme on Socio-Economic Security of the ILO. The larger collection conducted each survey using a national collaborating team under the responsibility of ILO's staff. For additional information, see Anker (2002), who coordinated the People's Social Survey (PSS) for cross-cultural comparability. The total sample $(n=8198)$ included 4240 females and 3868 males. The urban households sampled had respondents between ages 15 and 64 years. In Argentina, the number of cases was 2800, in Brazil, 4000 cases, and in Chile, 1180 cases. While these samples are not representative of the national populations, Anker (2002) points out that previous empirical analysis carried out in Chile and Brazil indicate that the efficiency of this sampling procedure tends to be quite similar to that based on pure probabilistic sampling (see Mercedes \& Caceres, 2002). The participants specifically chosen for this study were those who were part of the survey section for respondents who were employed. Then employees who also reported that they were sexually harassed in the past two years were the respondents tested for perceiving sexual harassment. As Friedrich et al., (2006) point out, there are demographics and cultural differences between these populations; however, all women in the sampled South American countries experienced more difficulty advancing in the workplace than men. 


\section{$\underline{\text { Instrumentation }}$}

The ILO PSS data was collected with the purpose of reducing socio-economic insecurity. This study used a global measure similar to that used by the Navy Equal

Opportunity/Sexual Harassment Survey (NEOSH), "one of the most widely distributed surveys that has not been modified with each administration" (Culbertson \& Rodgers, 1997, p. 1958) and by others (Adams-Roy \& Barling, 1998; Cortina, et al., 1998; Magley, Hulin, \& Fitzgerald, 1999). For the present study, the samples used were exclusively individuals who were employed. The exact questions this survey asked in order to measure sexual harassment, sexual aggression, and job satisfaction can be found in Table 1.

The three surveys analyzed for this study were in Spanish for Argentina and Chile and in Portuguese for Brazil. The data was collected between January and April 2001 in the three largest metropolitan areas of each of these countries. In Argentina, the three areas sampled were Buenos Aires, Rosario, and Cordoba; in Brazil, they were Sao Paulo, Rio de Janeiro, and Recife; and in Chile, they sampled the metropolitan area of Greater Gran Santiago.

Table 1 - Operationalization of Independent and Dependent Variables

Variable Name Variable Description

$\overline{\mathrm{X} 1}$ Sexual Harassment $\quad$ During the past two years, have you experienced sexual harassment at work or school? 1.Yes 2.No.

X2a. Sexual Aggression

X2b. Sexual Aggression

X3 Age

X4 Education
Did you ever suffer any kind of violence? 1.Yes 2.No.

If yes, which kind? 1. Hold-up 2 Robbery 3. Physical

Aggression 4. Sexual Aggression 5. Other

What is your age?

What is your highest degree of schooling? $(1=$ none,

2 = elementary incomplete, 3 = elementary completed, 4

$=$ high school incomplete, $5=$ high school completed, $6=$

college incomplete, $7=$ college completed, $8=$ Master or

Doctoral degree completed

X5 Sex
Are you Male or Female $?$ 
Y1 Job Satisfaction

\section{Results}

To test R1 and R2, separate multivariate analyses of variance (MANOVAs) were computed. MANOVA results answered RQ1 by showing that South American employees experiencing sexual harassment in South America did not have lower job satisfaction than employees not experiencing sexual harassment. Answering RQ2, results showed that South American employees experiencing sexual aggression in South America have lower job satisfaction than South American employees not experiencing sexual aggression.

Sexual harassment was entered as the independent variable and job satisfaction (wages) and job satisfaction (benefits) were the dependent variables. There was no multivariate main effect for sexual harassment. To test Hypothesis 2, sexual aggression was entered as the independent variable and job satisfaction (wages) and job satisfaction (benefits) were the dependent variables. The MANOVA produced a significant multivariate main effect for sexual aggression (Wilk's $\lambda=.98, F[2,1379], \eta^{2}=.02$ ) $=4672.91, p<.0001, \eta^{2}$ $=.87$ ) showing multivariate analysis was warranted.

Univariate analysis for the dependent variable of job satisfaction (wages) revealed a significant main effect for sexual aggression, $F(1,1382)=12.37, p<.0001$. Comparing the means for participant job satisfaction (wages) indicated that those experiencing sexual aggression in the workplace $(M=2.84 ; S D=1.12)$ reported having less job satisfaction (wages) than those not experiencing sexual aggression $(M=3.07 ; S D=$ 1.14). Similarly, when comparing the means for participant job satisfaction (benefits), those experiencing sexual aggression in the workplace reported having less job satisfaction (benefits) $(M=2.72 ; S D=1.16)$ than those not experiencing sexual aggression $(M=3.05 ; S D=1.27)$.

\section{Discussion}

The purpose of this study was to test whether perceptions of sexual harassment differ between South American and U.S. employees. Results based on their job satisfaction ratings indicated that South American employees are less concerned about sexual harassment in its milder form. In particular, while U.S. studies show that both sexual 
harassment and sexual aggression results in lower job satisfaction (Houghtalen, 2001; Lim \& Cortina, 2005; Shupe et al., 2002), South American data show that only when South American employees experience the more serious form of harassment, namely, sexual aggression, does their job satisfaction suffer.

\section{Implications Based on Collectivism and Power Distance}

R1 asked whether South American employees experiencing sexual harassment in South America will not have lower job satisfaction than employees who are not experiencing sexual harassment. Results showed that there was no decrease in job satisfaction associated with experiencing sexual harassment. Collectivistic cultures tend to emphasize concern for the needs of the group before those of oneself (Hofstede, 2001; Tavakoli et al., 2003). In addition, the relatively high PD in South American cultures contributes to an acceptance of those in authority. Combined with South American interpretations of machismo as embracing dignity and respect, it appears that employees just accept sexual harassment and do not take it personally, as is evidenced by the lack of impact sexual harassment has on job satisfaction among South American employees. On the one hand, sexual harassment could be so rampant that people simply tolerate it. On the other hand, since it is tolerated, it is possible that people from South America wonder why the Americans make such a big issue about sexual harassment. This type of assumption has implications for both perpetrators and targets of sexual harassment.

First, if the perpetrator of sexual harassment is not reprimanded for this type of behavior, it will continue unchecked. In that case, if the perpetrator and target are both South American and the target has no job dissatisfaction, then there is no problem that has to be addressed. Next, if a multinational organization sends a South American perpetrator to the US to work, there could be major implications if sexual harassment takes place with a U.S. employee. For example, employers could have to contend with hostility, conflicts, and reduced job satisfaction of U.S. employees, and their subsequent absenteeism, turnover, and possible lawsuits because research shows that U.S. employees response this way to being sexually harassed. The last case, if U.S. employees are sent to a South American base of operations, they could feel put upon and harassed while those in the South American culture would not understand what the issue is and consequently would not do anything about the sexual harassment. This could possibly lead to greater absenteeism and illness by U.S. employees as well as U.S. expatriates coming home or leaving the firm altogether.

\section{Implications Based on Masculinity}

Major cultural differences between the US (which is masculine) and two (i.e., Chile and Brazil) of the three South American countries tested (which are feminine) explain how, according to Hofstede, cultures that are masculine have more sex differences than feminine cultures, which are more egalitarian in that they do not strongly differentiate between the roles of men and women (Hofstede, 1998). Moreover, Hofstede (1998) posits that women from feminine cultures are much less likely to experience unwanted 
intimacies as "sexual harassment" because in feminine cultures, unwanted intimacies are not considered to be such a big issue, as opposed to those from masculine cultures where sexual harassment is a big issue. In addition, Schwartz (1993) also finds this to be the case in his findings that those in feminine Sweden have much fewer feelings of being sexually exploited than respondents in the masculine US generally. These differences in perceptions are important to investigate further because the implications for communication in multinational businesses are many.

DeSouza et al. (2007) described Brazilians as having a greater degree of individualism than Hofstede (2001) originally indicated because in their study Brazilians accused others of sexual harassment more strongly than those in the individualistic US. It is possible, however, that these findings could also be explained by the enormously high rate of sexual harassment and sexual aggression present in Brazil (Fiedler \& Blanco, 2006; Merkin, 2007). People could feel so overwhelmed by more severe forms of sexual harassment that they simply must speak up.

Furthermore, other studies have pointed out that theorists tend to misstate differences in psychological functioning related to the MF dimension and incorrectly attribute them to the IC dimension (Hofstede, 1996; Merkin, 2005). While the majority of U.S. crosscultural studies focus on IC, including DeSouza et al.'s (2007) study, MF is the cultural dimension most connected to sex differences (Hofstede, 1996; G. Hofstede, personal communication, July 10,2007$)$. Thus, it is worthwhile to examine cross-cultural perceptions of sexual harassment with MF in mind. It is possible that DeSouza et al.'s (2007) interpretation of their findings could also reflect changes in South American countries indicating that they have become more masculine (Diekman, et al., 2005) in their move from agrarian societies to more urban, industrial, and capitalistic societies (Smith \& Korzeniewicz, 1997; Stark, 2001).

\section{Implications Based on Uncertainty Avoidance}

Although sex differences may not be prominent in South American countries as a parameter of sexual harassment, another societal characteristic that could differentiate the three samples used in this study from other cultural samples is their strong UA. In fact, findings regarding R2, that asked if South American employees experiencing sexual aggression in South America have lower job satisfaction than employees not experiencing sexual aggression, showed this to be the case. While South American employees may be more lax with sexual harassment, sexual aggression crosses the line as to what is tolerated. Thus, both South Americans and U.S. Americans object to sexual aggression. Practically speaking, multinationals in high-UA cultures might want to be on the lookout for such problems within South American subsidiaries before transferring U.S. employees to South America and vice versa.

\section{Limitations and Future Research}

This research was carried out on a purposive sample using a closed-ended questionnaire. Although the sample is very large, the items measuring sexual 
harassment and sexual aggression were only one-item measures thus, precluding the possibility of asking follow-up questions. Thus, this preliminary analysis is limited to what was measured, but necessary nonetheless, given the dearth of information on sexual harassment in South America. Another limitation of this study was the implicit comparison of South American perceptions with those in the US. A new data collection was not undertaken for this study partly because there is such a wide range of literature already available on how sexual harassment is perceived in the US and partly due to lack of resources.

As Friedrich, Mesquita, and Hatum (2006) point out, value-belief theories such as Hofstede's (2001), which identify values and beliefs held by members of cultures and link them to actions and behavior, can also over-generalize the nuances of South American cultures. On the other hand, while there are distinct cultural differences found with regard to privacy needs and openness to women in leadership roles in the Argentina, Brazil and Chile, with regard to the context of South American women advancing, all South American women sampled by Friedrich et al., (2006) experienced more difficulty advancing in the workplace than men. Thus, to combine Argentina, Brazil, and Chile to discuss sexual harassment using a heuristic and parsimonious framework seems warranted.

Additionally, while Hofstede's cultural dimensions provide a heuristic framework to help understand South American perspectives, the high individualism present in the US may not completely account for the US intolerance of others that leads to rampant litigation and conflict. This general U.S. cultural trait of intolerance leading to litigation could be responsible for a competing influence as to whether people perceive issues such as work conflicts and sexual harassment to be really sexual harassment or not. Thus, there is a possibility that this test may be capturing a generic tendency of whether a society as a whole emphasizes litigation or not goes as opposed to the confines of dimensions of collectivism and individualism exclusively. On the other hand, there is evidence that members of weak PD cultures engage in more litigation because of their just world beliefs. Future research is necessary to rule out possible confounding variables such as litigation tendencies, religious beliefs (Protestantism, Catholicism), beliefs towards universalism (as opposed to relativism), and other possible characteristics. Thus, while the conclusions made are based on statistical evidence, there are also limitations in this analysis.

The hypotheses in this study are drawn from previous findings grounded in Hofstede's (2001) cultural dimensions. But more qualitative open-ended follow-up questioning would help corroborate the conclusions of these findings. This analysis is a beginning towards understanding more fully the situation in Argentina, Brazil, and Chile with regard to sexual harassment. Future investigations can now follow up with more indepth questions to back up this study's findings.

In particular, while research has indicated that cultural collectivism and a strong PD indicate an acceptance of inequality and injustice (Furnham, 1993; Hofstede, 2001), a likelihood not to inform on a sexual-harassment perpetrator, and lower propensities for 
whistle-blowing reporting (Patel, 2003; Sims and Keenan, 1999; Tavakoli, et al., 2003), the assumption that targets of sexual harassment would be less likely to whistle-blow has not been directly tested in Argentina, Brazil, and Chile. Thus, future research is warranted to ask respondents about their actual intentions to whistle-blow on perpetrators of sexual harassment.

In general, questions reflecting the values of collectivism, PD, UA, and MF are necessary to further corroborate conclusions. For example, Arrindell \& Hofstede (1998) point out that sexual harassment is not present in feminine cultures generally because the women tell the men in clear terms what their sexual needs are. They explain that in feminine cultures there is more of a sense of equality. Employees from feminine cultures will not hesitate to speak up; and bosses are more likely to be responsive to their wishes. Thus, sexual harassment in feminine cultures seems to be of a different variety than in masculine cultures. Consequently, more in-depth research is needed to investigate these differences in detail to identify the specific elements of the values behind the different perceptions of sexual harassment between South American and U.S. employees. However, the findings of this study have moved sexual harassment research forward by providing initial conclusions and by giving direction for the South American managerial sexual harassment studies of the future.

\section{References}

Adams, J. D. (1988). A healthy cut in costs. Personnel Administrator, 33, 42-47.

Adams-Roy, J., \& Barling, J. (1998). Predicting the decision to confront or report sexual harassment. Journal of Organizational Behavior, 19, 329-336.

Anker, R. (2002). People's security surveys: An outline of methodology and concepts. International Labour Review, 141, 309-329.

Arrindell, W. A., \& Hofstede, G. H. (1998).Masculinity and femininity: The taboo dimension of national cultures. Thousand Oaks, California: Sage.

Baba, V. V., Jamal, M., \& Tourigny, L. (1998). Work and mental health: A decade in Canadian research. Canadian Psychology, 39, 94-107.

Barak, A. (1997).Cross-cultural perspectives of sexual harassment. In W. O'Donohue (Ed.) Sexual Harassment: Theory, research, and treatment, pp. (263-300). Boston, MA: Allyn \& Bacon.

Bergman, M. E., Langhout, R. D., Palmieri, P. A., Cortina, L. M., \& Fitzgerald, L. F. (2002). The (Un)reasonableness of Reporting: Antecedents and Consequences of Reporting Sexual Harassment. Journal of Applied Psychology, 87, 230-242. 
Bond, M.A , Punnett, L., Pyle, J. L Cazeca, D., \& Cooperman, M. (2004). Gendered Work Conditions, Health, and Work Outcomes. Journal of Occupational Health Psychology, 9, 28-45.

Chan, D. K. S., Tang, C. S. K., \& Chan, W. (1999). Sexual harassment: A preliminary analysis of its effects on Hong Kong Chinese women in the workplace and academia. Psychology of Women Quarterly, 23, 661-672.

Cocroft, B. K., \& Ting-Toomey, S. (1994). Facework in Japan and the United States. International Journal of Intercultural Relations, 18, 469-506.

Cortina, L. M., Fitzgerald, L.F., \& Drasgow, F. (2002). Contextualizing Latina experiences of sexual harassment: Preliminary tests of a structural model. Basic and Applied Social Psychology, 24, 295-311.

Cortina, L. M., Swan, S., Fitzgerald, L. F., \& Waldo, C. (1998). Sexual harassment and assault: Chilling the climate for women in academia. Psychology of Women Quarterly, 22, 419-441.

Cortina, L. M., \& Wasti, S. A. (2005). Profiles in Coping: Responses to Sexual Harassment Across Persons, Organizations, and Cultures. Journal of Applied Psychology, 90, 182-192.

Culbertson, A. L. \& Rodgers, W. (1997). Improving managerial effectiveness in the workplace. The case of sexual harassment of Navy women. Journal of Applied Social Psychology, 27, 1953-1971.

Dansky, B. S., \& Kilpatrick, DG. (1997). Effects of sexual harassment. In O'Donohue W (Ed.), Sexual harassment: Theory, research, and treatment. Needham Heights, MA: Allyn \& Bacon.

DeSouza, E. R., \& Hutz, C. (1996). Reactions to refusal of sexual advances among US and Brazilian men and women. Sex Roles, 34, 549-565.

DeSouza, E. R., Pryor, J.B., \& Hutz, C. (1998). Reactions to sexual harassment charges between North Americans and Brazilians. Sex Roles: A Journal of Research, 39, 913-925.

DeSouza, E. R., \& Solberg, J. (2003). Incidence and dimensions of sexual harassment across cultures. In C. A. Paludi Jr. \& M. Paludi (Eds.) Academic and workplace sexual harassment: $A$ handbook of cultural, social science, management, and legal perspectives (pp. 3-30). Westport, Conn: Praeger.

DeSouza, E. R., Solberg. J. \& Elder, C. (2007). A cross-cultural perspective on judgments of woman-to-woman Sexual Harassment: Does sexual orientation matter? Sex Roles, $A$ Journal of Research, 56, 473-482. 
Diekman, A. B., Eagly, A. H., Mlandinic, A., \& Ferreira, M. C. (2005). Dynamic stereotypes about women and men in South America and the United States. Journal of Cross-Cultural Psychology, 36, 209-226.

Duska, R. (1997). Whistle-blowing in P. Werhane and R. Freeman (eds) Encyclopedic Dictionary of Business Ethics. Oxford: Blackwell.

Elman, R. A. (1996) Sexual politics and the European Union: The new feminist challenge. Providence, Rhode Island: Berghahn Books.

Felix-Ortiz, M., Abreu, J. M., Briano, M., \& Bowen, D. (2001). A critique of Machismo measures in psychological research. In F. Columbus (Ed.), Advances in psychological research (vol. 3, pp. 63-90). Hauppage, NY: Nova Science.

Fiedler, A. M., \& Blanco, R. I. (2006). The Challenge of Varying Perceptions of Sexual Harassment: An International Study. Journal of Behavioral and Applied Management, 7, 274-291.

Fitzgerald, L.F., Drasgow, F., \& Magley, V. J. (1999). Sexual harassment in the Armed Forces: A test of an integrated model. Military Psychology, 11(3), 329-343.

Friedrich, P. F., Mesquita, L. F., Hatum, A. O. (2006). The Meaning of Difference - beyond cultural and managerial homogeneity stereotypes of South America. Management Research, 4(1): 53-71.

Furnham, A. (1993). Just world beliefs in twelve societies. Journal of Social Psychology, 133, 317329.

Gilson, L. L., Fedor, D. B., \& Roth, J. L. (2005). What is fair and to whom? Fairness evaluations of socio-sexual behavior. Journal of Managerial Issues, 17, 293-309.

Glomb, T. M., Munson, L. J., Hulin, C. L., Bergman, M. E., \& Drasgow, F. (1999). Structural equation models of sexual harassment: longitudinal explorations and cross-sectional generalizations. Journal of Applied Psychology , 84, 14-28.

Good, G. E. \& Sherrod, N. B.(2001). The psychology of men and masculinity: Research status and future directions. In Rhonda Unger (Ed.) Handbook of psychology and gender (pp. 201-215). Hoboken, NJ: John Wiley.

Gruber, J. E. (1992). A typology of personal and environmental sexual harassment: Research and policy implications form the 1990's. Sex Roles, 22, 447-464.

Gruber J. E. (2003). Sexual harassment in the public sector. In Paludi M., \& Paludi C. A., Jr. (Eds.), Academic and workplace sexual harassment: A handbook of cultural, social science, management, and legal perspectives. Westport, CT: Praeger/Greenwood. 
Gruber, J. E., \& Bjorn, L. (1982). Blue collar blues: The sexual harassment of women autoworkers. Gender \& Society, 9, 271-298.

Gudykunst, W. B., \& Ting-Toomey, S. (1988). Culture and affective communication. American Behavioral Scientist, 31, 384-400.

Gutek, B. A. (1985). Sex and the workplace. San Francisco, Josses-Bass.

Gutek, B. A. \& Koss, M. P. (1993). Changed women and changed organizations: Consequences of and coping with sexual harassment. Journal of Vocational Behavior, 42, 1-21.

Hanisch, K. A., \& Hulin, C. L (1990). Job attitudes and organizational withdrawal: An examination of retirement and other voluntary withdrawal behaviors. Journal of Vocational Behavior, 37, 60-78.

Hofstede, G. (1997) Cultures and Organizations: Software of the Mind. London: McGraw-Hill.

Hofstede, G. (1996). Gender stereotypes and partner preferences of Asian women in masculine and feminine cultures. Journal of Cross-Cultural Psychology, 27, 533-546.

Hofstede, G. (1998). Masculinity and Femininity: The Taboo Dimension of National Cultures. Thousand Oaks, CA: Sage Publications.

Hofstede, G. (2001). Culture's consequences: Comparing values, behaviors, institutions, and organizations across nations. Thousand Oaks, CA: Sage.

Houghtalen, R. P. (2001). Sexual Aggression. Community Mental Health Journal, 37(6), 542-543.

Huerta, M., Cortina, L. M., Pang, J. S. Torges, C. M., \& Magley, V. J. (2006). Sex and Power in the Academy: Modeling Sexual Harassment in the Lives of College Women. Personality and Social Psychology Bulletin, 32, 616-628.

Husted, B. W. (1999). Wealth, culture, and corruption. Journal of International Business Studies, 30, 339-360.

Kim, U., Triandis, H., Kagitcibasi, C., Choi, S., \& Yoon, G. (1994). Individualism and Collectivism: Theory, Method and Applications. Newbury Park, CA: Sage.

Krahe, B. (2001). The social psychology of aggression. New York: Psychology Press.

Kublin, K. (1987). The Japanese negotiation style: Cultural and historic roots. Industrial Management, 29, 18-23. 
Leung, K., Bhagat, R. S., Buchan, N. R., Erez, M., \& Gibson, C. B. (2005). Culture and international business: Recent advances and their implications for future research. Journal of International Business Studies, 36, 357-378.

Lim, S., \& Cortina, L. M. (2005). Interpersonal Mistreatment in the Workplace: The Interface and Impact of General Incivility and Sexual Harassment. Journal of Applied Psychology, 90(3), 483-496.

Luthar, V. K., \& Luthar, H. K. (2002). Using Hofstede's cultural dimensions to explain sexually harassing behaviours in an international context. International Journal of Human Resource Management, 13, 268-284.

MacNab, B., MacLean, J., Brislin, R. Aguilera, G. M., \& Worthley, R. (2007). Culture and ethics management: Whistle-blowing and internal reporting within a NAFTA country context. International Journal of Cross Cultural Management, 7, 5-28.

Magley, V. J., Hulin, C. L., \& Fitzgerald, L. F. (1999). Outcomes of self-labeling sexual harassment. Journal of Applied Psychology, 84, 390-402.

Matsui, T., Kakuyama, T., Onglatco, M-L, \& Ogutu, M. (1995).Women's perceptions of socialsexual behavior: A cross-cultural replication. Journal of Vocational Behavior. 46, 203-215.

Matsumoto, Y. (1988). Reexamination of the universality of face: Politeness phenomena in Japanese. Journal of Pragmatics, 12, 403-426.

Mercedes, M., \& Caceres, J. (2002). More training, less security? Training and quality of life at work in Argentina, Brazil, and Chile. International Labour Review, 141, 359-383.

Merkin, R. (2005). The Influence of Masculinity-Femininity on Cross-Cultural Facework Journal of Intercultural Communication Research, 34, 267-289.

Merkin, R. (2006). Power distance and facework. Journal of Intercultural Communication Research, 35, 139-160.

Merkin, R. (2007). Antecedents of Sexual Harassment in Argentina, Brazil, and Chile. Paper presented at the annual meeting of the International Academy of Intercultural Research, Groningen, The Netherlands.

Merkin, R. (2008). The Impact of Sexual Harassment on Turnover Intentions, Absenteeism, and Job Satisfaction: Findings from Argentina, Brazil, and Chile. Journal of International Women's Studies, 10, 73-91.

Miner-Rubino, K., \& Cortina, L. M. (2004). Working in a Context of Hostility toward Women: Implications for Employees' Well-Being. Journal of Occupational Health Psychology, 9, 107-122. 
Moffett, M. (2006, March 13). Politics \& Economics: Chile Mirrors a Fading Machismo: Nation's Female President Highlights Women's Gains in South American Politics. Wall Street Journal, p. A. 8.

Morrow, P. C., McElroy, J. C., \& Phillips, C. M. (1994). Sexual harassment behaviors and work related perceptions and attitudes. Journal of Vocational Behavior, 45, 295-309.

Munson, L. J., Hulin, C. L., \& Drasgow, F. (2000). Longitudinal analysis of dispositional influences and sexual harassment: Effects on job and psychological outcomes. Personnel Psychology, 53, 21-46.

Narodowski, M. (1999). Educational Research in South America: A Response to Akkary and Pérez. Education Policy Analysis Archives, 7, ERIC Online Clearinghouse on Assessment and Evaluation.

O'Connell, C. E., \& Korabik, K. (2000). Sexual harassment: The relationship of personal vulnerability, work context, perpetrator status, and type of harassment to outcomes Journal of Vocational Behavior, 56(3), 299-329.

Patel, C. (2003). Some Cross-cultural Evidence on Whistle-blowing as an Internal Control Mechanism. Journal of International Accounting Research, 2, 69-97.

Pryor, J. B., Desouza, E. R., Fitness, J., Hutz, C., Kumpf, M., Lubbert, K., Pesonen, O., \& Wang, E. M. (1997). Gender differences in the interpretation of social-sexual behavior: A crosscultural perspective on sexual harassment. Journal of Cross-Cultural Psychology, 28, 9-34.

Quick, J. C., Murphy, L. R., \& Hurrell, J. J. (1992). Stress and well-being at work: Assessments and interventions for occupational mental health. Washington, DC: American Psychological Association.

Rospenda, K. M., Richman, J. A., Ehmke, J. L. Z. \& Zlatoper, K. W. (2005).Is workplace harassment hazardous to your health? Journal of Business and Psychology, 20, 95-110.

Safa, H. I. (1976). Class consciousness. In J. Nash \& H. I. Safa (Eds.) Sex and class in South America. New York: Praeger Publishers.

Schwartz, S. H. (1993, July). Toward explanations of national differences in value priorities. Presented at the XXIV Congress of the Interamerican Society of Psychology, Santiago de Chile.

Shaffer, M. A., Joplin, J. R. W., Bell, B. P., Lau, T., \& Oguz, C. (2000). Gender discrimination and job-related outcomes: A cross-cultural comparison of working women in the United States and China. Journal of Vocational Behavior 57, 395-427. 
Shupe, E. I., Cortina, L. M., Ramos, A., Fitzgerald, L. F., \& Salisbury, J. (2002). The incidents and outcomes of harassment among Hispanics and non-Hispanic white women: A comparison across level of cultural affiliation. Psychology of Women Quarterly, 26, 298-308.

Sigal, J., \& Jacobsen, H. (1999).A cross-cultural exploration of factors affecting reactions to sexual harassment: Attitudes and policies. Psychology, Public Policy, and Law, 5, 760-785.

Sigal, J., Gibbs, M. S., Goodrich, C., Rashid, T., Anjum, A., Hsu, D., Perrino, C. S., Boratav, H. B., Carson, A., Baarsen, B., van der Pligt, J., \& Pan, W-K. (2005). Cross-cultural reactions to academic sexual harassment: Effects of individualist vs. collectivist culture and gender of participants. Sex Roles, 52, 201-215.

Sims, R., \& Keenan, J. (1999). A Cross-cultural Comparison of Managers' Whistle-blowing Tendencies. International Journal of Values-Based Management, 12, 137-151.

Smith, W. C., \& Korzeniewicz, R. P. (1997). Politics, social change, and economic resructuring in South America. Coral Gables, FL: North-South Center Press.

Stark, J. (2001). The challenge of change in South America and the Caribbean. Coral Gables, FL: North-South Center Press.

Stoga, A. (2002). For better or worse, South America's too important to the U.S. to ignore. The Miami Herald, June 9.

Stohl, C. (1993). European manager's interpretations of participation: A semantic network analysis. Human Communication Research, 20, 97-117.

Stevens, E. (1973). Machismo and marianismo. Society, 10(6), 57-63.

Tavakoli, A., Keenan, J., \& Crnjak-Karanovic, B. (2003) 'Culture and Whistle-blowing: An Empirical Study of Croatian and United States Managers Utilizing Hofstede's Cultural Dimensions'. Journal of Business Ethics, 43, 49-64.

Timmerman, G., \& Bajema, C. (1999) Incidence and methodology in sexual harassment research in northwest Europe. Women's Studies International Forum, 22,6, 673-681.

Triandis, H. (1988). Individualism and collectivism. Boulder, CO: Westview Press.

Valdes, L. F., Baron, A., \& Ponce, F. Q. (1987). Counseling Hispanic men. In M. Sher, M. Stevens, G. Good, \& G. Eichenfield (Eds.) Handbook of counseling and psychotherapy with men (pp. 203-217). Newbury Park, CA: Sage.

Vitell, S. J., Nwachukwu, S. L., \& Barnes, J. H. (1993). The effects of culture on ethical decisionmaking: An application of Hofstede's typology. Journal of Business Ethics, 12, 753-761.

West, C. (1982). Doing Difference. Work and Occupations, 9, 271-298. 
Williams, C. L., Giuffre, P. A., \& Dellinger, K. (1999). Sexuality in the workplace: organizational control, sexual harassment, and the pursuit of pleasure. Annual Review of Sociology 25, 73-93.

Zippel, K. (2004). Transnational advocacy networks and policy cycles in the European Union: The Case of Sexual Harassment. Social Politics, 11, 57-85.

\section{Author's Notes}

The author wishes to thank the International Labour Office's InFocus Programme on Socio-Economic Security, especially Jose Burle Figueredo and Hilary Silver, for making these data available. Thanks too to Maria Jeria and Richard Anker for details about the sampling for these data sets. An earlier version of this paper was presented at the International Communication Association conference held in Montreal, Canada, May, 2008. 